\title{
An Exploratory Research on Virtual Reality and How It Affects Future of Shopping and Immerging Fields
}

\author{
Saurabh Sharma and Christian Bach
}

\begin{abstract}
As we move towards future the advancement in technology and its methodologies are taking place more frequently than imagined. In every single stream the changes are vivid prominent, whether it be Computers, Genetic engineering or Nano technology. On this run we have generated the whole new dimension of technology known as virtual reality or (VR), this investigation is focused on its related field and the impact that virtual reality persists over the future of fast growing technologies specifically on augmented reality and shopping.
\end{abstract}

Index Terms - Virtual Reality; Augmented Reality; Internet Shopping; Augmented-Virtual-Reality; Future Technology; Virtual Reality Simulations; Biomedical; Education.

\section{INTRODUCTION}

Virtual Reality (VR) is creating innovation that has remarkable and very genuine business applications not just in entertainment outlets, VR applications hold market of shopping, biomedical, infrastructure, education and defense fields among numerous others.

With the critical study we can now discover precisely how virtual reality functions, where it's going, and what affect it will have on future industry in the years ahead. This examination provides understandable reference and gives the total picture of how VR is being utilized today and its potential for tomorrow, stuffed with priceless and straightforward data. This research also uncovers requirements to make a virtual world including equipment, and software, to systems administration abilities, to partially sound/video prerequisites and coordination of the different components.[1]

However, our main focus is on digging the co-relation of this technology with the innovative and existing application and implementing it in real-world shopping experience. On contrary, the existing framework with easy to understand and appealing User Interface (UIs) would give higher consumer satisfaction which leads to difficult transformation but with the inclination of individuals to utilizing the benefits of the growing framework for obtaining, promoting, and different application purposes the

Published on December 10, 2016.

S. Sharma and C. Bach are with University of Bridgeport, USA. (e-mail: sausharm@my.bridgeport.edu) business has started experimenting and has started working in the direction predicted to get accepted soon in many fields. [2]

\section{DEFINING VIRTUAL REALITY}

Since the beginning virtual reality has uncertain history[3], different definitions and missing inventor. When we look at the words separately we can observe:

Virtual: not physically existing as such but appear to be so.

Reality: the state of things as it actually exists.

General definition of Virtual Reality derived from the above-mentioned information will be, experiencing the existing in a place, which doesn't exist in actual state. The more technical definition of virtual reality would be, a computer generated considered existence not physically existing but a program generated. VR is an artificial experience that is generated with programming and presented to the user in a manner that the users get convinced and acknowledges it as a genuine experience. On a personal computer, virtual reality is essentially experienced through two of the five senses: sight and sound.[4]

\section{Companies view on Virtual Reality}

There are various companies working over this combination of virtual and augmented reality. Below mentioned are some of the very big companies how are working with good intensity to bring VR in the market for all users.

$\begin{array}{ll}\text { - } & \text { Alphabet } \\ \text { - } & \text { Go-pro } \\ \text { - } & \text { Facebook } \\ \text { - } & \text { Apple } \\ \text { - } & \text { AMD } \\ \text { - } & \text { Qualcomm }\end{array}$

Reference [5] also shows that business in the west coast and other parts of United States has already started using this technology for their advertisement and displaying product. Points incorporate from [6] shows how San Diego retailer Jerome's Furniture is utilizing the innovation as a part of offering its furniture, the enthusiasm of Qualcomm Ventures, a wander subsidize in San Diego, in a few organizations working in augmented reality and virtual reality are few examples of innovation and its uses in fields. 
Figure below displays that major companies (approx. 60\%) have invested their money on headset and $30 \%$ on game development, which are based on augmented reality and renaming $10 \%$ is divided into other peripheral, camera technology and social network platforms[6].

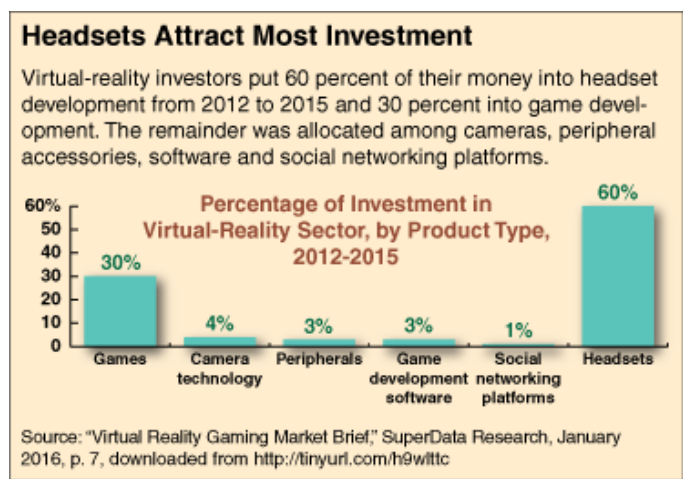

Fig. 1. The percentage of investment in VR sector by product type [7]

\section{MARKET OF VIRTUAL REALITY}

By evaluating the recorded pictures from the source[7] the anticipated growth in the market of simple game development (3\%) can be seen in figure displayed below.

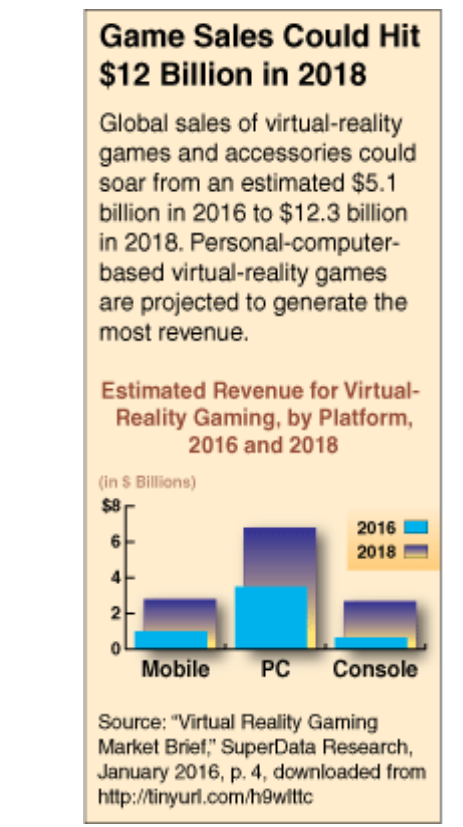

Fig.2. The inclination in the market w.r.t VR

The estimated growth in the sales growth of market $\$ 5.1$ billion in year 2016 to 12.3 billion in 2018 which is just personal computer and then there is mobile gaming and consoles also so by this example we can anticipate the growth in the market in the related fields[6].

\section{IMPLEMENTATION OF VIRTUAL REALITY IN}

\section{VARIOUS FIELDS}

The implementation of virtual reality takes place in various sectors in different industries and is expanding rapidly. And with this speed the growth of the market, which is surely affecting the growth of the sub-related fields. It is estimated that in coming decade, VR is going to be the next big things in the market and will be merging with diverse fields. Few of the sectors are discussed below

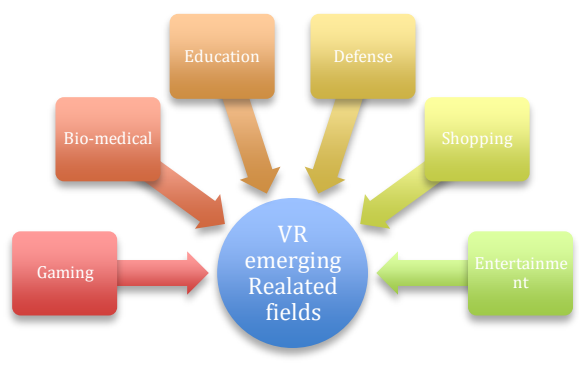

Fig. 3. The current VR emerging fields

\section{A. Bio-medical with VR}

New advancements, specifically virtual reality innovations are majorly affecting health care in the past decade. Clinically approved, effective medicinal test systems are presently accessible and being used over the world. General surgery and stroke rehabilitation[8] leads in the utilization of test systems, and neurosurgery leads with augmented reality and picture-guided surgery. Virtual reality is playing a very vital role in defining the future of bio medical in various sub-divisions, considerable in terms of surgery domain. Inventors are designing the simulation, which can provide real feel of surgery without performing actual surgery on people. Which in my opinion is one of the best uses of VR with respect to entertainment side[9].

However, other virtual reality applications are also being utilized as a part of emotional wellness, anesthetics, and crisis pharmaceutical. Fast advancements in the web and "elearning" spaces have fastened the scattering of simulation systems, intuitive 3D pictures, and organized courseware.

\section{B. Challenges related with implementing virtual reality in surgery.}

It's a long road ahead, as the beginning of the new era in surgery; it is facing many challenges like, a thought about the technical education to the medical professionals develops technical uneasiness and alien feeling which are genuine issues as medicinal experts. A research shows that beyond the age 30 years it becomes difficult to learn new technologies and concepts and known as "lost era" concerning information technology [10] [11] .

Although the NHS is presently attempting to introduce informatics with health facilities specialists and has had 
been steering the presentation of the European Computer Driving authority, which is regulating up distinctly qualification and capability for future occupations consideration with information technology[12]. The way European and US improvements in micro-laser and micromanipulators is exemplary, the da Vinci Surgical System, are currently being utilized for master-slave robotics techniques, for example, negligibly obtrusive coronary artery bypass grafting and laparoscopic surgery is proof of the utilization of virtual reality innovation suggest that an insurgency in medicinal instruments and in the preparation of the individuals who utilize it nearer individuals that counted.[13].

However, with regards to the early endeavors to present advances, virtual reality and robotics are merging into same markets, similarities are in restorative phase and will be required with expectation to learn and adapt this system. It is also anticipated that the advances as of now accomplished and the upcoming discoveries are subjected to merge with the health care science and related subjects[14].

\section{Cinematography with $V R$}

Cinematography with VR takes visual narrating higher than ever. The viewers are engaged and experience a reality from the different perspective. It generates a whole new experience for the viewers with the details never experienced before. Altogether it demands to create a new ground for the moviemakers as for them, controlling the VR cinematography experience utilizing standard gadgets is not possible, as an example, close-ups, or through video altering.

So, moviemakers need to utilize the fundamentals of shooting as well, light, sound, and action and the new immerging gadgets with varying demands to draw the viewer's attention.

The virtual reality cinematic experience can be generated by software oriented (augmented reality) or a genuine recording live-activity video in 360 degrees requires uncommon camera frameworks. Equipment's used to generate this experience are very expansive, some of them consist with 16 cameras in a roundabout cluster[15]. Few are little less-costly cameras looks like ball with two fisheye lenses. Some of them shoot stereoscopic video, which includes another immersive 3D quality. Others shoot level 2D monocarpic video, which still has a 3D feeling since it wraps around in 360 degrees[16].

While cinematic VR is picking up in fame, various companies are innovating applications and with their VR oriented programs. With the help of those programs unsafe situations and high-hazard exercises can be securely replicated and observed multiple times and a lot of time and energy investment can be saved[17].

\section{BENEFITS OF VIRTUAL REALITY}

Virtual reality has considered having multiple benefits in the areas of health science, education, sports and many more. It is also very profitable in terms of saving a large amount spends in actual performance study of defense and human behavior. Some of them are described and discussed in this research paper.

\section{A. Public Speaking and Anxiety Issues}

One study found that fear of speaking in can be diminished by about 20 percent in the matter if four weeks only with VR. The South Korean study had 27 members speaking to virtual groups on the security related issues of their homes. They were instructed through a program that tested them to present themselves to the virtual groups, meet-ups, conferences, and public gatherings. This VR program brings to the finishing activities to raise a toast at a wedding and a give presentation. Toward the end of the program, participants were requested to present to a genuine public. Nine of ten members had a reduced anxiety issue more confident eye contact, and were find to give answers calmly[17].

\section{B. Athletic Training}

Five National Football League groups and 9 football groups for schools are as of now utilizing VR to prepare their quarterbacks. A round camera on the field records their sessions while they are practicing. Which enables the player to practice the same scenario again and again without the danger of injuries. This supports the team and its players to produce much stronger and well-practiced team players as they most of the quarterback are now able to practice more. Quarterbacks who prepared in the VR test system enhanced basic leadership by 30 percent, and where able to take decisions faster than usual[17].

\section{ShOPPING With VIRTUAL Reality SimUlatoR}

Shopping with VR is expanding rapidly with the huge expectation of growth in market in terms of advertisement and marketing. Although in fact it is facing a lot of trouble as it is still in its early stage and changing very quickly. Virtual Reality experience is doing considerable growth with the expectation of providing useful shopping measures which may also improve experience of genuine execution, far beyond existing psychological test techniques, and give an additional time-productive strategy for assessing genuine results in constantly changing business environment[18]. The investigation had been designed in a particular way to find out the future of virtual reality in terms of shopping with respect to the highly acceptable and needed areas.

For the starters the research is specifically optimized for the youngsters between age group of 18 to 35 , as they are more adaptive and have easy access to the equipment's required for VR shopping when compared to more mature people from the age 50 and above because the research 
acknowledges that the main source of vision loss for individuals takes place above 50 is mostly age-related macular degeneration. Other reasons responsible for low vision are diabetic retinopathy, glaucoma, and cataract[19]. However excessive behavioral demand for attention produces trouble in managing ordinary activities like cooking and driving can create mental stress in life for older people[20]. This study recognized attention requests of elderly individuals. And especially the people living in the cold and rainy region where heavy snowfall or rainfall occurs through a long period of year which has considered as they can have a direct impact on the retail market as the climatic conditions are not very comfortable to go out for shopping[21].

\section{INTERVIEW PROCESS}

The interviews were conducted among various individuals from the age group of 18 to 70 years. Mostly living in United States of America, belong to different regions but are currently in United States coming from different backgrounds. Interviewers were not convinced or perceived in any scenario neither their opinions are tampered. Total 20 interviewers were considered during this process.

\section{A. Gender Analysis}

Gender identity model predicts that items are hastily purchased to reflect self-identity. Hence gender, as an important social categorization, should effect both the items purchased spontaneously and by critical analysis of utilized. This research explores parts of motivation for purchasing in different gender through individual meetings and utilizing them for quantitative and open-ended measures. As a general anticipation, men tend to purchase relaxation and instrumentals that displays independence, while ladies tend to purchase symbolic and self-expressive products as a concerned with appearance and related emotions of self. From the total number of volunteer interviewers $55 \%$ were females and $45 \%$ were male, majority from both the genders shows inclination towards the virtual reality[22]. Which helps in conceding that VR is not just connects emotionally but also gives a sense of independence and is accepted by both the genders.

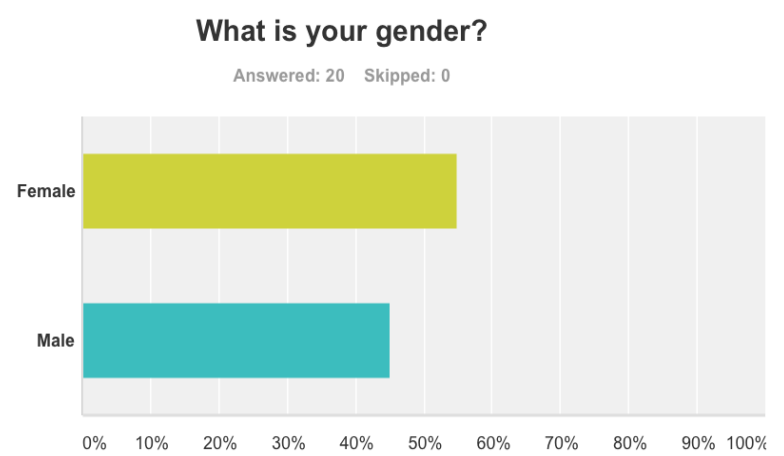

Fig. 4. The ratio of male/female participant

TABLE I: THE GENDER PARTICIPATION AND PERCENTAGE

\begin{tabular}{lll}
\hline Gender & Response & Percentage \\
\hline Female & 11 & $55 \%$ \\
\hline Male & 9 & $45 \%$ \\
\hline Total & 20 & $100 \%$ \\
\hline
\end{tabular}

\section{B. Age variation}

During this research part the age is given special consideration, which opens the door to future investigation. Out of total input collected $45 \%$ candidates were between the ages of 18 to 24 years, $45 \%$ were 25 to 34 years and remaining $10 \%$ were 55 above. Retailing supervisors can make utilization of the outcomes as depicting multifaceted nature of Internet shopping and purchasing conduct. Age contrasts (in both bearings) were seen for some item classifications. Furthermore, comes about show that how one web based shopping impacts on one's comprehension of age consequences for web shopping. Age corresponded with online pre-shopping look yet was decidedly associated with web based acquiring[23]. In this case it turns out to be contradictory as the participants support VR and online shopping but are not sure about the user friendliness and have dice opinion.

TABLE II: AGE DISTRIBUTION OF PARTICIPANTS

\begin{tabular}{lll}
\hline Age Group & Response & Percentage of Total \\
\hline $\mathbf{1 8}$ to $\mathbf{2 4}$ & 9 & $45 \%$ \\
\hline $\mathbf{2 5}$ to $\mathbf{3 4}$ & 9 & $45 \%$ \\
\hline $\mathbf{5 5}$ and above & 2 & $10 \%$ \\
\hline Total & 20 & $100 \%$ \\
\hline
\end{tabular}




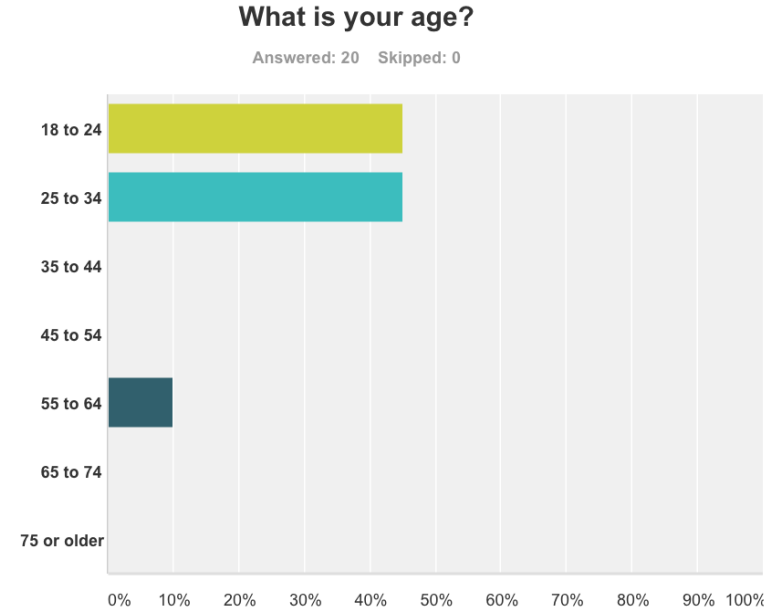

Fig. 5. Contribution of different age in survey.

\section{Resident of Country}

Most of the candidates were from East Coast of United States, in figurative description total $90 \%$ of collected opinions are from people who are staying in east coast for more than 6 months, and the reaming $10 \%$ are from other region.

TABLE III: CURRENT COUNTRY PARTICIPANT LIVING IN

\begin{tabular}{llll}
\hline $\begin{array}{l}\text { Current Country of } \\
\text { residence }\end{array}$ & Response & Percentage of Total \\
\hline $\begin{array}{l}\text { United States of } \\
\text { America }\end{array}$ & 18 & $90 \%$ \\
\hline Others & 2 & $10 \%$ \\
\hline Total & 20 & $100 \%$ \\
\hline
\end{tabular}

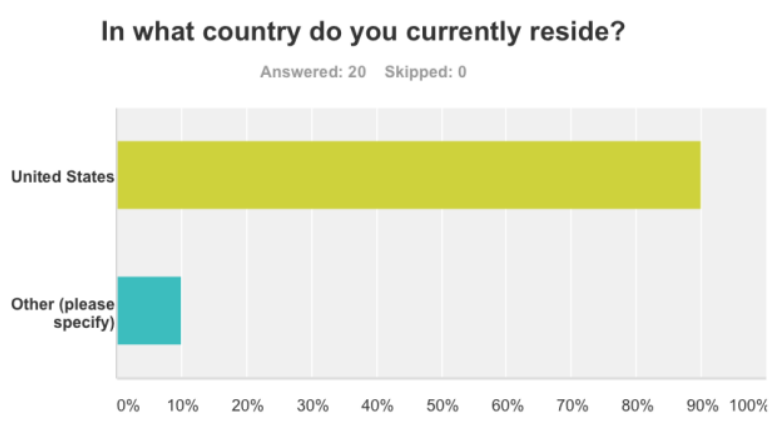

Fig. 6. Current residence of participant

\section{Country of Birth}

The investigation of country of-origin (COO) impacts analyzes how customers perceive items from a specific nation. This review analyzes country -of-origin as far as the fit amongst nations and products. A system is proposed which coordinates the significance of item class measurements with the apparent picture of the nation ofbeginning along similar measurements. The companies launching products can utilize such matches to generate more confidence in the approach of company. It simplifies the process of selecting nation coordinate data to analyze consumers expectations, and help them in dealing with their item's based of country of origin[24].

TABLE IV: TOTAL PARTICIPANTS FROM DIFFERENT ORIGINS

\begin{tabular}{lll}
\hline Reviewer's Country & Response & Percentage of Total \\
\hline India & 7 & $35 \%$ \\
\hline China & 1 & $5 \%$ \\
\hline Turkey & 1 & $5 \%$ \\
\hline Russia & 1 & $5 \%$ \\
\hline Nigeria & 1 & $5 \%$ \\
\hline United States & 1 & $5 \%$ \\
\hline Pakistan & 1 & $5 \%$ \\
\hline Brazil & 1 & $5 \%$ \\
\hline Saudi Arabia & 3 & $15 \%$ \\
\hline Others & 3 & $15 \%$ \\
\hline Total & $\mathbf{2 0}$ & $\mathbf{1 0 0 \%}$
\end{tabular}

To get in the depth of reviewer, the country from which they belong was also collected, which also helped in better understand of the origin of opinion and perspective development. Majority (35\%) of the candidates are from India, 5\% of the candidate's response was collected individually from China, Turkey, Russia, United State, Pakistan and Nigeria, which in total comes out to be $25 \%$ of the total survey. $15 \%$ reviewers were from Saudi Arabia and remaining $15 \%$ were from Other regions. This study shows that even the participants are from varying regions but after staying in United Stated for over six months they have collected a sufficient knowledge about virtual reality that they are willing to try it and are expecting great result. Another reason for the same argument can be marketing and promotion by the companies working on virtual reality and it seems they have done fantastic work. One another contradictory argument can be related to the entertainment side, positive reply participants are in the range of 18 to 35 years and the futuristic movies and advertisement seems to have taken over their thoughts about virtual reality, as per the amount spent monthly by the participant, VR devices and peripheral devices are much expansive. 


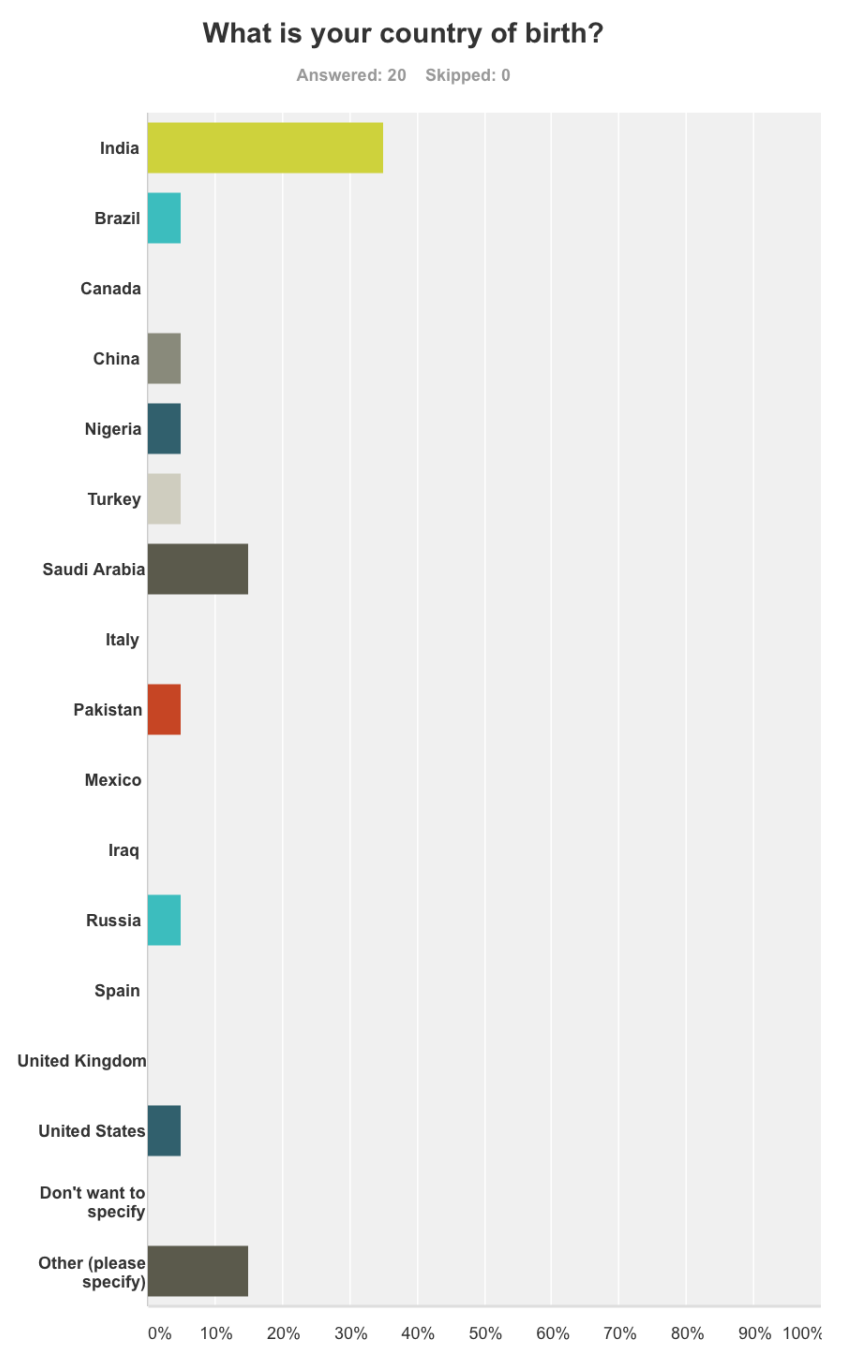

Fig. 7. Displays the origin of participant.

\section{E. Amount spent in U.S Dollar monthly}

After collecting the origin and perspective development this research was driven into the spending behavior of reviewers over the Internet that was to analyze the confidence and the comfort level with making transactions over the Internet.

TABLE V: RANGE OF AMOUNT SPENT By PARTICIPANT IN A MONTH

\begin{tabular}{lll}
\hline $\begin{array}{l}\text { Money Spent } \\
\text { (In Dollars) }\end{array}$ & Number of Response & Percentage of Response \\
\hline $\mathbf{\$ 0}-\mathbf{\$ 2 0}$ & 2 & $10 \%$ \\
\hline $\mathbf{\$ 2 1}-\mathbf{\$ 5 0}$ & 5 & $25 \%$ \\
\hline $\mathbf{\$ 5 1}-\mathbf{\$ 1 0 0}$ & 7 & $35 \%$ \\
\hline $\mathbf{\$ 1 0 1}-\mathbf{\$ 2 0 0}$ & 5 & $25 \%$ \\
\hline More than $\mathbf{\$ 2 0 0}$ & 1 & $5 \%$ \\
\hline Total & $\mathbf{2 0}$ & $\mathbf{1 0 0 \%}$ \\
\hline
\end{tabular}

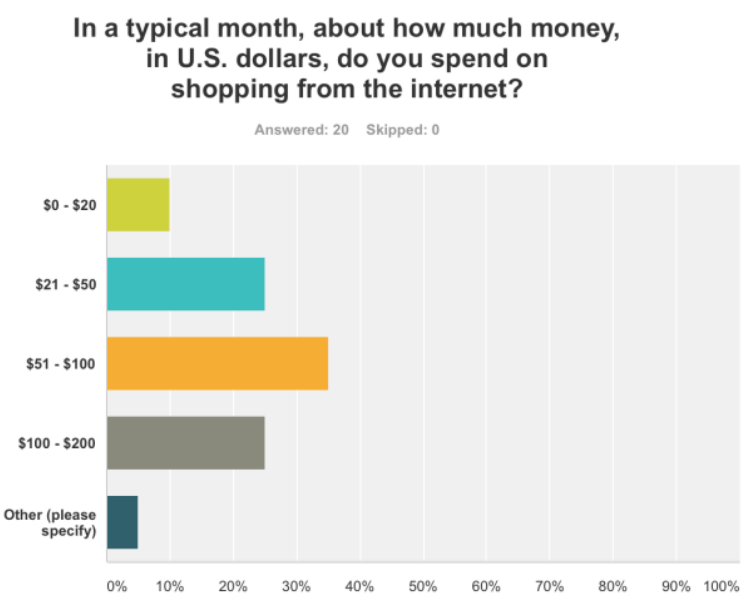

Fig. 8. the amount spent monthly by participants.

\section{F. Support towards Virtual Reality}

Our research also focuses on the knowledge and support reviewing candidates have towards the Virtual reality from the very beginning of this new era. The responses were as follows

TABLE V: INTEREST OF PARTICIPANTS IN VR

\begin{tabular}{lll}
\hline Support Virtual Reality & Response & Percentage of Total \\
\hline Yes & 12 & $60 \%$ \\
\hline No & 4 & $20 \%$ \\
\hline Not Interested & 4 & $20 \%$ \\
\hline Total & $\mathbf{2 0}$ & $\mathbf{1 0 0 \%}$ \\
\hline
\end{tabular}

Do you support Virtual Reality Shopping?

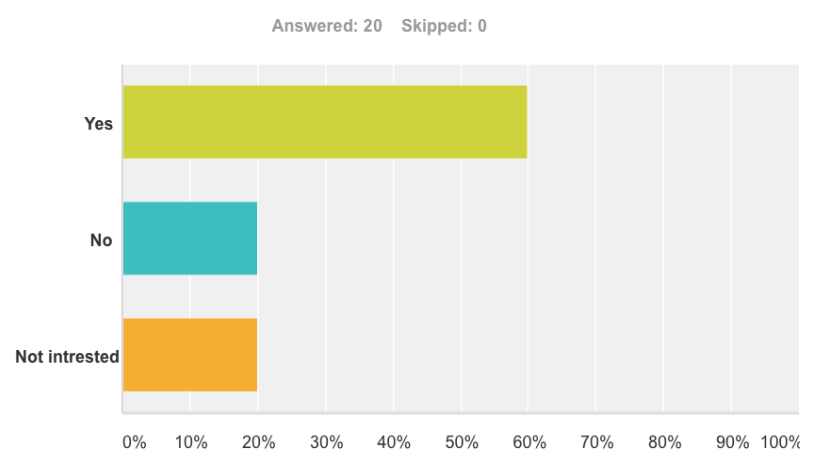

Fig.9. Inclination of participant towards VR.

Which shows that majority are willing to experiment with the virtual reality shopping and they have an expectation of it being a successful technology for the future. 
Question 1

In your opinion what is the future of online shopping?

\begin{tabular}{|l}
\hline Participant 1 \\
"I think it is very essential in life now days and it is doing great"
\end{tabular}

Participant 2

"I think it is going to end very soon as the market is changing rapidly."

Participant 3

"I think the online shopping is doing great."

Participant 4

"It is going great, it is so helpful. It reduces the time consumption and ease the life style with multiple options."

Participant 5

"It is going to end soon."

Participant 6

"It is taking over the general retailer market and creating more completion"

\section{Participant 7}

"It is little complicated and must be more descriptive for non technical person."

Participant 8

"It will take over shopping malls"

Participant 9

"Providing 24/7 live chat support to answer any shopping related questions

Allowing sample trails first of the clothes and then allowing leeway for

choosing whatever we want in it"

Participant 10

"I think it is going to take over the stores"

Participant 11

"The product specifications should be properly mentioned and the

delivered product should meet all the specifications."

Participant 12

"In future online shopping will overtake the physical market"

Participant 13

"Everything set up at the digital today's world. So I believe online market has extremely good buying potential."

Participant 14

"It is going to widen and become more competitive as it has made life of people easy so it's going to get even bigger in the future"

Participant 15

"I think online shopping can be enhanced in a way that people get aware of it as fast as possible through this it will have bright future."

Participant 16

"It will do great. It will be a great innovation."

Participant 17

"Online shopping has made our lives freaking easy and it is way better than going to stores as it gives more variety and is cheaper than buying from stores."

Participant 18

"Online shopping is the future. With companies like amazon and eBay online shopping has become the one stop-shopping destination for a lot of people with little to no access to department stores."

Participant 19

"No Response"

Participant 20

"No Response"

By looking at the response of the participants it can be observed that online shopping has already become an essential part of daily life and people have realized that it has made daily chores more convenient. Although participants have also mentioned about the competition and effect that online shopping has on current shopping malls and retail shops in the market. Majority has accepted online shopping and are using it thoroughly, some of the participants also mentioned about the lack of technical knowledge and support services and improvements in their suggestion/opinion which also helps in concluding that consumers are looking for something more or an improvement in the internet/online shopping.

Question 2

What is your opinion about Virtual reality shopping?

Participant

"Don't know."

Participant 2

"Virtual reality has a good scope in future and will create a great

experience and convenience for user."

Participant 3

"I think it is going to be very expensive but will be useful in certain

scenarios."

Participant 4

"I think it will be create a very competitive environment for the smallscale industries."

\section{Participant 5}

"It has a lot of time to come out in market for the general user."

Participant 6

"It is going to be very expensive and will not be excepted in small towns, but it is new innovation and should be promoted."

Participant 7

"It seems new, if it is made easy and more covenant than it will be more

successful than regular shopping"

Participant 8

"I prefer it"

Participant 9

"Fashion stylists can look at our sense of style and suggest personalized clothing"

Participant 10

"It is time consuming."

Participant 11

"It's going to make shopping experience better"

Participant 12

"No idea"

Participant 13

"Virtual reality is a new modernize way to promote shopping trend"

Participant 14

"I believe that Virtual reality shopping makes people to "going shopping ". It's becoming more and more. For example eBay, amazon etc. are very successful and leading the market at this area."

Participant 15

"This is a great concept as it gives we the consumers the urgency for convenience and feasible shopping."

Participant 16

"It has everything that a customer would want. Easy access, low cost, cost

savings in terms of travel cost. This, virtual shopping is much better as

compared to shopping in store."

Participant 17

"Virtual reality shopping is great idea and as people already are into online shopping in websites like Amazon and eBay so it would be unique and will be fun to do"

\section{Participant 18}

"It will be very helpful and this innovation will be successful in a large scale."

Participant 19

"It can be the next big thing!!!"

Participant 20

"Virtual Reality is the future shopping of online shopping. Currently inaccessible to the public, virtual reality has the potential to change the outlook of online shopping"

When the participants were asked to give their opinion about virtual reality, the most surprising part was that they were already aware about the VR technology, which implies that companies are marketing their product very effectively and users are experiencing and promoting it. Although most of the participants were sure that VR is 
going to take over shopping malls and will help in making better decisions, majority was also concerned about the pricing of the devices along with peripherals, adapting the new technology, which concludes to be worried about the user friendliness of complete system. Most of the candidates anticipated that it has a long run to come in market for general user and small industries.

\section{ADAPTATION OF THE IMPLEMENTATION}

The adaptation of new technology has always been a very long but relatively fast process, if we look at the growth in last decade with respect to technology and its adaptation a lot has changed and it is a continues process of development and improvisation. However when a completely new field comes into the pictures of technology it does not stick automatically, it takes time and lot of efforts to adapt technology [25].

\section{Problem with Adaptation}

Some of the major problems in adapting a new system are consideration of relative advantage and comparing it with the cost. Another reason is compatibility of values, needs and experience of that particular technology in this case VR.

General Categories of Problems with simple solution

$\begin{array}{ll}\text { - } & \text { Relative Advantages } \\ \text { - } & \text { Cost } \\ \text { - } & \text { Need } \\ \text { - } & \text { Experience } \\ \text { - } & \text { Compellability } \\ \text { - } & \text { Trainability } \\ \text { - } & \text { Risk }\end{array}$

However the complexity, trainability and risk associated with the product and consumer is also a very big factor in accepting the technology and it will plays a major role in deciding the adaptation factor of VR[26]. The motive of this research is to recognize and understand the attitudinal, social, furthermore, behavioral control figures that are essential in disclosing expectations to adopt Virtual Reality Technology. The total study briefly describes multidimensional way to deal with extensively understanding expectations of user with new technology.

If companies are able to overcome these challenges and can provide Perceived Benefits to the users while removing unwanted Barriers and imposing the Importance of Compliance to a demanded standard, with the advancement of technology that makes task easy in real life and provides better sync with the user.

\section{CONTRIBUTION AND CONCLUSION}

In the world of technology new products and technologies are coming out at very fast rate and with the most of the companies and users are trying to keep up with the speed of change[27] reaching the final goal will be modified rapidly. In my opinion the time for introducing something new to the user is when they are less resistance towards experimenting otherwise companies get confused between the customer demands and requirements[28]. This investigation and interview process defines virtual reality in the present state and how it is affecting different sectors, including the challenges VR is facing in its implementation regarding the detailing and capturing the actual environment and providing real feel to its users as per expectation. Through this research we have also discuss the effect of VR in Bio-medical field and its effect in terms of surgery and how overcoming different challenges be more useful which enables to work in the direction of surgery in terms of bio-medical. In this paper little light is also thrown on entertainment side of virtual reality along with peripheral devices, like which are the companies who have already produced and launched their VR product in market and has been utilized by other professional for VR production. A detailed market of VR also shows the growth to be 3 times of present in 2018 in terms of entertainment and gaming, whose effect can already be seen on many companies and their strategies in building a game and VR cinematic experience, due to which various related start-ups are been promoted in market with intense rate. Which also opens a market for opportunist, which will create several jobs in present market. This also gives scope of training and installing facilities on different grounds depending upon the region and its acceptance rate. Leading behavioral and circumstantial challenges are also discussed which are creating trouble in accepting the new technology are one of the major points for the companies and professionals that will help to mold the structure of industry according and focusing on both the factors economic growth and social growth. As per research people are comfortable with the existing market and have finally settled the way to get social along the way and now VR introduction is enhancing the experience a lot more is expected.

Our outcomes demonstrate that individuals who spend more online have a more wired way of life, are on the Net, and get more email compared to other Internet clients. As Internet utilize diffuses throughout the overall, this profile is becoming increasingly normal[29]. Data collected with the process of interviews and analyzed over different variables gives a very vivid description of virtual reality. Research shows that participants from the age 18 to 34 are very much open to accept the VR and specifically in terms of both the gender (male and female) are similar which indicates the gradual market expansion. Investigation also goes through participants from different origin living in the same country, surprising result comes out when compared, 90\% of distinct participants are living in United States of America from last six months or more and from that $60 \%$ have shown interest in Virtual Reality, Out of which $90 \%$ have are regular at present online shopping system, which 
means active users of present system are willing to divert towards VR market, in my opinion it is a very good start for VR[29].

However, the adaptation of new technology is going to be difficult and will take time but according to the study consumers seems more worried about the cost that comes along with the new system, also it will be add-on step in eliminating the current retail shops market system. All the study, analysis and data collection makes this research a valuable contribution in the field of virtual and augmented reality. Companies and candidates looking for the generalized concept and specific details related to VR will find this paper very useful. Additionally this study also helps in knowing market associated with VR and user anticipation with the different fields of work taking place in different sectors and can be used as a potential starting point for the research ahead[30]. To sum up, companies and users' needs to work hand in hand to create a real feel experience in using virtual reality. Market looks open for new technology and can lead to a good start with high competitive environment. It has many challenges and unanswered question but from current perspective it is completely defined to workhand to overcome those difficulties for the better world. Virtual reality is a game changer in terms of augmented reality and is going to affect major sectors and will change the way consumers look at things. It is too early to discuss the boundaries of virtual reality but so far it shares a very keen interest of consumers and companies and with this mutual interest soon we will see a complete new world dominate by virtual reality.

\section{REFERENCES}

[1] Larijani, C.C., The Virtual Reality Primer. 1993: McGraw-Hill, Inc. 274.

[2] Lee, K.C. and N. Chung, Empirical analysis of consumer reaction to the virtual reality shopping mall. Computers in Human Behavior, 2008. 24(1): p. 88-104.

[3] Hosseini, A. and M. Lienkamp. Enhancing telepresence during the teleoperation of road vehicles using HMD-based mixed reality. in Intelligent Vehicles Symposium (IV), 2016 IEEE. 2016. IEEE.

[4] Rouse, M. Virtual Reality. 2015 May 2015 11/29/2016]; Available from: http://whatis.techtarget.com/definition/virtual-reality.

[5] Bruno. Top 10 VR Companies. 2016 [cited 2016; Available from: http://www.ultravr.org/virtualreality/top-10-vr-companies/ 1_Alphabet.

[6] Graves, B., Virtual and Augmented Reality Look to Fit in the Big Picture. San Diego Business Journal, 2016. 37(29): p. 6.

[7] Marshall, P., Virtual Reality. CQ Research 2016. 26(9).

[8] Laver, K., et al., Virtual reality for stroke rehabilitation. Stroke, 2012. 43(2): p. e20-e21.

[9] Valmaggia, L.R., et al., Virtual reality in the psychological treatment for mental health problems: An systematic review of recent evidence. Psychiatry Research, 2016. 236: p. 189-195.

[10] Ray, N.M. and R.P. Minch, Computer anxiety and alienation: Toward a definitive and parsimonious measure. Human Factors: The Journal of the Human Factors and Ergonomics Society, 1990. 32(4): p. 477-491.

[11] Kidd, M.R. and W. McPhee, The "lost generation": IT education for healthcare professionals. The Medical Journal of Australia, 1999. 171(10): p. 510.
[12] Chaudhry, A., et al., Learning rate for laparoscopic surgical skills on MIST VR, a virtual reality simulator: quality of human-computer interface. Annals of the Royal College of Surgeons of England, 1999. 81(4): p. 281.

[13] McCloy, R. and R. Stone, Virtual reality in surgery. British Medical Journal, 2001. 323(7318): p. 912.

[14] McCloy, R. and R. Stone, Science, Medicine, And The Future: Virtual Reality In Surgery. BMJ: British Medical Journal, 2001. 323(7318): p. 912-915.

[15] Cutting, J.E., How the eye measures reality and virtual reality. Behavior Research Methods, Instruments, \& Computers, 1997. 29(1): p. 27-36.

[16] Wong, B., Target IoT Applications, 2016, Penton Media, Inc. p. 4848.

[17] Gronstedt, A., from immersion to PRESENCE. TD: Talent Development, 2016. 70(6): p. 54-59.

[18] Greenwood, K.E., et al., Virtual shopping: A viable alternative to direct assessment of real life function? Schizophrenia Research, 2016. 172(1-3): p. 206-210.

[19] N/A, Breakthrough in Adaptive Reading Technology Opens New Doors for Millions With Impaired Vision; Pulse Data Debuts myReader(TM), a Revolutionary Reading Device for People With Age-Related Macular Degeneration and Other Degenerative Eye Diseases, 2004.

[20] Jansen, D.A. and M.L. Keller, Identifying the Attentional Demands Perceived by Elderly People. Rehabilitation Nursing, 1998. 23(1): p. 12-20.

[21] Starr-McCluer, M., The effects of weather on retail sales. 2000: Divisions of Research \& Statistics and Monetary Affairs, Federal Reserve Board.

[22] Dittmar, H., J. Beattie, and S. Friese, Gender identity and material symbols: Objects and decision considerations in impulse purchases. Journal of Economic Psychology, 1995. 16(3): p. 491-511.

[23] Sorce, P., V. Perotti, and S. Widrick, Attitude and age differences in online buying. International Journal of Retail \& Distribution Management, 2005. 33(2): p. 122-132.

[24] Roth, M.S. and J.B. Romeo, Matching product catgeory and country image perceptions: A framework for managing country-oforigin effects. Journal of international business studies, 1992. 23(3): p. 477-497.

[25] DiPietro, R.B., et al., Key issues for ICT applications: impacts and implications for hospitality operations. Worldwide Hospitality and Tourism Themes, 2010. 2(1): p. 49-67.

[26] Tan, M. and T.S. Teo, Factors influencing the adoption of Internet banking. Journal of the AIS, 2000. 1(1es): p. 5.

[27] Subramaniam, M., Integrating Cross-Border Knowledge for Transnational New Product Development. Journal of Product Innovation Management, 2006. 23(6): p. 541-555.

[28] Morgan, J., et al., An application of Taguchi method of experimental design for new product design and development process. Assembly Automation, 2006. 26(1): p. 18-24.

[29] Bellman, S., G.L. Lohse, and E.J. Johnson, Predictors of online buying behavior. Communications of the ACM, 1999. 42(12): p. 3238.

[30] Leung, L., Impacts of Net-generation attributes, seductive properties of the Internet, and gratifications-obtained on Internet use. Telematics and Informatics, 2003. 20(2): p. 107-129. 


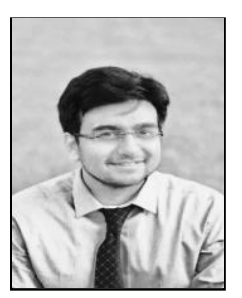

Saurabh Sharma (India/August 10, 1989).

Masters in Technology Management, University of

Bridgeport, Bridgeport, CT, USA. December 2016.

He Co-Founded a company in India and has worked

with several start-ups and company professionals

through the globe. Mr. Sharma is a member of

Society of Women Engineering, and Engineering without orders. 